\title{
Treatment Possibilities for Psychosis in Parkinson's Disease with An Emphasis on the Newly Approved Drug: Pimavanserin
}

\author{
Zsófia Majláth ${ }^{1}$, Izabella Obál ${ }^{1}$ and László Vécsei ${ }^{12^{*}}$ \\ ${ }^{I}$ Department of Neurology, Faculty of Medicine, Albert Szent-Györgyi Clinical Center, University of Szeged, H-6725 \\ Szeged, Semmelweis u. 6, Hungary; ${ }^{2}$ MTA-SZTE Neuroscience Research Group, H-6725 Szeged, Semmelweis u. 6, \\ Hungary
}

\section{A R T I C L E H I S T O R Y}

Received: June 19, 2016

Revised: September 06, 2016

Accepted: September 23, 2016

DOI:

$10.2174 / 18715273156661610061043$

\begin{abstract}
Parkinson's disease (PD) is a progressive neurodegenerative disorder with prominent motor and non-motor symptoms. Psychosis develops in over $40 \%$ of PD patients and it is one of the most distressing symptoms for patients and caregivers alike. Until recently, atypical antipsychotics, clozapine and quetiapine were used to treat psychotic symptoms, but treatment was associated with substantial concerns for side-effects of clozapine and unfounded efficacy for quetiapine. Extensive research has shown that the antipsychotic effect of these drugs could be attributed to serotonin 2 a receptor $\left(5-\mathrm{HT}_{2 \mathrm{a}}\right)$ triggered mechanisms. A selective 5- $\mathrm{HT}_{2 \mathrm{a}}$ inverse agonist, pimavanserin, has been developed, investigated and has gained approval in April 2016 in the US for the treatment of hallucinations and delusions in PD. In this review we primarily focus on psychosis in PD, the current treatment possibilities and the new, emerging therapy, pimavanserin, a selective 5- $\mathrm{HT}_{2 \mathrm{a}}$ inverse agonist. All articles were reviewed in this topic and indexed in PubMed with keywords: Parkinson's disease psychosis, serotonin 2a receptor inverse agonist, clozapine, quetiapine, pimavanserin.
\end{abstract}

Keywords: Clozapine, Parkinson's disease psychosis, pimavanserin, quetiapine, serotonin 2a receptor inverse agonist.

\section{INTRODUCTION}

Parkinson's disease (PD) is a neurodegenerative disorder which is characterized by motor and non-motor symptoms. Incidence of Parkinson's disease is $4-20 / 100,000$ while prevalence is $0.3 \%$ in industrialized countries [1]. The number of PD patients is constantly increasing, thus inducing more vigorous research in the field. A range of symptomatic treatments is available for motor symptoms, mainly targeting dopamin receptor activation or levodopa supplementation. However, effective therapy for non-motor symptoms is eagerly awaited. Non-motor symptoms include depression, apathy, fatigue, impulse-control disorders, sleep disturbances and in $40-60 \%$ of patients, psychosis and dementia [2]. Psychosis consists of a wide spectrum of phenomena including hallucinations, delusions and minor symptoms of illusions and sense of presence [3-5]. Visual hallucinations occur in $20-30 \%$ of drug-treated PD patients, whereas auditory and tactile hallucinations are seen in $48 \%$ and $23 \%$ of the cases, respectively $[6,7]$. Delusions are mainly characterized by jealousy and paranoia [8].

The etiology of PD psychosis is multifactorial. In the past, symptoms were solely accredited to side-effects of

\footnotetext{
*Address correspondence to this author at the Department of Neurology, University of Szeged, Faculty of Medicine, Albert Szent-Györgyi Clinical Centre, Semmelweis u. 6., H-6725 Szeged, Hungary; Tel: +36 62 545348; Fax: +36 62 545597; E-mail: vecsei.laszlo@med.u-szeged.hu
}

dopaminergic medication, anticholinergics and other PD drugs. Presently, however, it is thought, that both extrinsic and intrinsic factors contribute to the development of psychiatric symptoms in PD.

Antiparkinson therapy is considered the most important extrinsic factor together with various environmental stimuli, and intercurrent comorbidities. The effect of levodopa replacement has been emphasized, however, the cause and effect relationship is difficult to discern. Frequently psychotic symptoms emerge during drug dose modification or the introduction of levodopa. On the other hand, a clear correlation between psychotic symptoms and dose increase was not found $[2,9]$. A high dose intravenous challenge did not precipitate hallucinations [10]. Dopamin-agonists have also been implicated. Data suggest that patients on dopamineagonist therapy might be more prone to have hallucinations than patients on levodopa [11]. In addition, intercurrent infections and other comorbidities play a crucial part in the development of psychosis as extrinsic factors. They can cause delirium, but also trigger pathological processes, e.g.: through inflammation, which contribute to the underlying neurodegenerative pathomechanisms [12].

Intrinsic factors are fundamentally disease-related with degenerative processes involving several neurotransmitter systems in the brain, abnormalities of the visual system, the presence of cortical Lewy body pathology and brainstem 
sleep dysfunction $[13,14]$. The pathological process influences several aspects of the disease, which contribute greatly to the development of psychosis. The time of onset (early vs. late onset), severity and duration of the disease as well as the age of the patient, the subtype of PD are all determining factors [12].

It has been shown that certain psychiatric diseases can precede motor symptoms of PD and PD psychosis [15]. Prior depression and anxiety may occur with greater risk among PD patients and their relatives especially in early-onset PD $[16,17]$. A genetic contribution has been suggested in the background, by data showing, that relatives of early-onset PD patients with a compound heterozygous mutation in the parkin gene, without signs of PD, may have a higher risk of depression [18]. Nonetheless, there was no correlation between early-onset PD patients with parkin mutations and prior depression. A study from Taiwan showed a strong correlation between prior anxiety, affective disorders, schizophrenia and subsequent PD [19]. As opposed to this, other investigators found no association between preceding bipolar disorders or schizophrenia and PD [20].

Dementia is also closely associated with PD psychosis. Psychosis occurs more frequently in PD with dementia than without $[9,12]$.

Other studies investigated genetic causes in connection with PDP. From several polymorphisms studied, the $-45 \mathrm{C}>\mathrm{T}$ polymorphism of the CCK gene was found to have increased associations with hallucinations in PD [12, 21]. Glucocerebrosidase mutations also showed a close correlation with the development of psychosis [22].

Considering the above, at the appearance of psychosis, secondary causes (e.g. infection) have to be excluded first. If this yields no effect, then the current PD medication should be reconsidered with a focus on anticholinergics, tricyclic antidepressants, MAOB inhibitors, amantadine, and at the end dopamine agonists and levodopa [23]. In case of persistent and progressive symptoms, specific antipsychotic treatment should be implemented.

Until recently clozapine and quetiapine, two atypical antipsychotics, have been used in the treatment of PDP. These drugs produce significantly less D2 receptor blockade than typical antipsychotics, with clozapine bearing the highest affinity ratio for the $5-\mathrm{HT}_{2 \mathrm{a}}$ relative to $\mathrm{D} 2$ receptors amongst atypical antipsychotics and also acting on D4 receptors [24]. When introduced into the therapic regimen, they allow the continuation, even maximalisation of previous PD treatment without further worsening PD motor symptoms $[25,26]$. However, neither medication gained approval by the FDA (Food and Drug Administration) because of potential serious side effects, consequential need for frequent blood monitoring in case of clozapine and unconfirmed efficacy for quetiapine. From the two, clozapine is the drug which has shown efficacy and tolerability with monitorable safety risks in randomized clinical trials $[25,27,28]$. Additionally to controlling psychosis, clozapine has also reduced tremor and levodopa-induced dyskinesias. These effects, however, can be observed mostly at moderate or high doses, which are tolerated poorly $[25,29,30]$. Even with the introduction of the drug at low doses $(6.25-50 \mathrm{mg} / \mathrm{day})$, there are several side-effects, which constitute a major drawback. Agranulocytosis, neutropenia can occur, independent of the dose, in most cases at the beginning of the treatment. Therefore frequent blood checks are required, weekly for 6 months, then every other week for 6 months and then once a month. Myocarditis, which is also considered to be a hypersensitivity reaction, independent of the dose, is rare in PD. Sedation, orthostatic hypotension and hypersalivation are problems most likely resulting from $\mathrm{H}_{1}$ and alpha ${ }_{1}$ adrenoreceptor blockade $[26,31,32]$. The increased sedative effect of the drug potentiates the excessive daytime sleepiness seen in PD patients. Metabolic side effects (weight gain, hyperglycaemia) and anticholinergic effects seem to have a dosedependent relationship and, thus, they are seldom seen in PD patients [26, 33]. Prolactinaemia, which is a frequent sideeffect of haloperidol and risperidone treatment, cannot be observed during clozapine and quetiapine therapy. The drugs' combined affinity for $5-\mathrm{HT}_{2 \mathrm{a}}$ and $\mathrm{D}_{2}$ receptors achieve sufficient $5-\mathrm{HT}_{2 \mathrm{a}}$ receptor blockade in the hypothalamus to counteract the effects of $\mathrm{D}_{2}$ receptor blockade in the pituitary gland, which otherwise cause prolactin elevation in pure $\mathrm{D}_{2}$ antagonists [34]. The lack of motoric side-effects is attributed to the "fast-off dissociation" of clozapine from striatal dopamine D2 receptors compared with other antipsychotics [35].

Consequently, after consideration of the possible, serious side-effects associated with clozapine, physicians often prescribe quetiapine. It is generally well-tolerated, despite the frequent sedative, hypotensive effects and dizziness, and there is a clinical impression of effectiveness. Metabolic syndrome and anticholinergic effects are usually dosedependent. On the other hand, data concerning efficacy are controversial. Quetiapine was shown to be effective in openlabel trials in treating psychosis [36, 37]. Placebo-controlled, double-blind, randomized trials, however, concluded opposite results, with quetiapine failing to overpower placebo in the therapy of PDP [38-41].

Age-related factors have to be taken into consideration as well. Data show that old-age onset PD is associated with an increased frequency of psychosis, dementia, sleep disorders, autonomic, olfactory and sensory symptoms as opposed to early onset PD [42]. Medication-related psychotic symptoms in PD also appear at a later age, when comorbidites are more common as well. In case of both clozapine, and quetiapine, however, increased mortality, morbidity and adverse events have been documented in elderly, demented patients, which present a problem in treatment. After consideration of the findings, a black box warning was issued for the treatment of behavioral disorders in elderly patients with dementia by the FDA, in 2005. Later studies also verified these data in a study on patients with various forms of dementia, published in 2015 [43]. Quetiapine, which consistently proved to be less harmful than the other AP drugs studied, still increased mortality by $2.0 \%$ compared to the control group. Another study extended investigations specifically to patients with PDP [44]. Results reinforced earlier observations of higher mortality however they showed that the increased risk is not specific to dementia in PDP. The various AP drugs studied conferred different risks, with typical antipsychotics posing the greatest. Authors also concluded that PD disease related risk factors substantially predispose patients to adverse 
events and add to the increased risk of mortality compared to other dementia patients.

Treatment with quetiapine and clozapine in the elderly predisposes patients to other severe adverse events as well. Neuroleptic malignant syndrome (NMS) has been documented in the elder patient population, although much less frequently than with other antipsychotics. This is attributed to the different receptor affinity profile of clozapine and quetiapine, these medications having less antidopaminergic (D2) effect than other antypsychotics [45, 46]. In addition, both drugs can cause QT interval prolongation. It is advised to do ECG examination at baseline and pay increased attention to drug interactions.

Thus, the choice between antipsychotics is difficult. The boundaries of former treatments and steadily increasing number of patients with PDP emphasize the importance of the need for the development of new, safer treatments.

\section{THE IMPORTANCE Of 5-HT ${ }_{2 a}$ INVERSE AGO- NISM AND THE DEVELOPMENT OF PIMAVAN- SERIN}

The pathomechanism behind the development of psychotic symptoms and anti-psychotic therapy in Parkinson's disease is complex. Several neuronal receptor families have been implicated. Initial observations from the antipsychotic treatment of patients with first generation antipsychotics have proposed that their antipsychotic effect might be exerted through the blockade of limbic D2 dopamine receptors. Further drug development has led to the introduction of atypical antipsychotics with better efficacy and side-effect profile. The evaluation of the affinities of typical and atypical antipsychotic medication for dopamine receptor D1, D2 and $5-\mathrm{HT}_{2 \mathrm{a}}$ receptors, in the light of their antipsychotic effect, resulted in the hypothesis, that a more likely basis for antipsychotic activity is the blockade of $5-\mathrm{HT}_{2 \mathrm{a}}$ receptors $[47,48]$.

This theory is advocated by facts from both animal experiments and human studies of $5-\mathrm{HT}_{2 \mathrm{a}}$ receptors. Hallucinations can be provoked by the stimulation of cortical $5-\mathrm{HT}_{2 \mathrm{a}}$ receptors and can be abolished by selective $5-\mathrm{HT}_{2 \mathrm{a}}$ inverse agonists and antagonists [49]. Hallucinogenic compounds, e.g. lysergic acid diethylamide, psilocybin and mescaline display high affinity for $5-\mathrm{HT}_{2 \mathrm{~A}}$ receptors and the pharmacological or genetic inactivation of $5-\mathrm{HT}_{2 \mathrm{~A}}$ receptors inhibit the behavioral effects of hallucinogens in various species, including mice, rats and humans [50]. However, it is difficult to investigate hallucinations in animals. Behavioral animal models cannot exactly capture the disturbances of perception and cognition elicited by hallucinogens and it is currently uncertain if animals actually hallucinate and to what degree, since hallucinations are subjective experience that require self-report. Therefore, in animal studies a variety of specific responses are examined, such as changes in exploratory behavior, grooming, interruption of operant responding, head twitch response, etc. [50].

In schizophrenia patients, initial PET studies with clozapine and quetiapine attributed the antipsychotic effect of these medications to the preferential occupancy of D1 and D2 receptors [51, 52], PET studies performed later, on the other hand, demonstrated, that visual hallucinations in PD correlate with excessive 5- $\mathrm{HT}_{2 \mathrm{a}}$ neurotransmission [53]. PDP patients' neocortex at autopsy has also revealed increased $5-\mathrm{HT}_{1 \mathrm{a}}, 5-\mathrm{HT}_{2 \mathrm{a}}$ receptor density [54], and post-mortem analysis showed abnormalities of $5-\mathrm{HT}_{2 \mathrm{a}}$ receptors with increased serotonin binding in the inferior temporal cortex of PD patients with previously observed visual hallucinations [55]. In addition, two studies concluded that ondansetron, a $5-\mathrm{HT}_{3}$ receptor antagonist alleviated symptoms of psychosis in PD and schizophrenia patients [56, 57]. All of these data suggest that a drug with selective $5-\mathrm{HT}_{2 \mathrm{a}}$ inverse agonist properties might prove to be useful in the antipsychotic regimen either as an adjunctive treatment or a monotherapy. Several compounds were created, mainly by ACADIA Pharmaceuticals. The compound fitting the criteria was ACP-103 or pimavanserin [58]. Its pKi $(-\log \mathrm{Ki})$ for the human $5-\mathrm{HT}_{2 \mathrm{a}}$ receptor is 9.3 , having a 40 -fold selectivity over the $5-\mathrm{HT}_{2 \mathrm{c}}$ receptor and lacking affinity for the $5-\mathrm{HT}_{2 \mathrm{~b}}$ or $\mathrm{D}_{2}$ receptors [58]. As opposed to clozapine and quetiapine, pimavanserin does not influence $\mathrm{H}_{1}$ and alpha $\mathrm{a}_{1}$ adrenoceptors which are responsible for sedative and hypotensive effects [31]. On the whole, pimavanserin is a compound, acting primarily on serotonin receptors, which are uniquely implicated in the pathogenesis of PDP, without the side-effect profile of the previously used antipsychotics.

\section{PIMAVANSERIN AS A NOVEL THERAPY FOR PDP}

The structural characteristics of pimavanserin are very different from other APDs. The chemical formula of pimavanserin is (1-[(4-fluorophenyl) methyl]-1)1-methylpiperidin-4-yl)-3[[4-(2-methylpropoxy) phenyl]methyl]urea) (Fig. 1) [58].

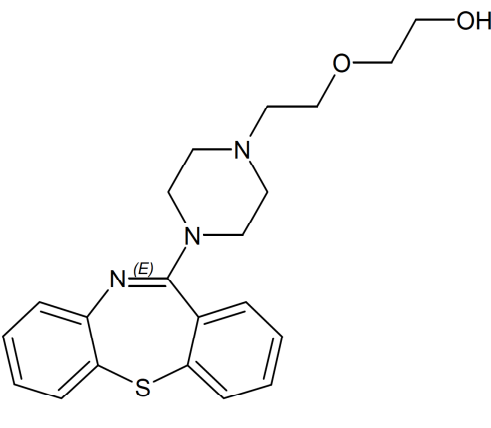

quetiapine

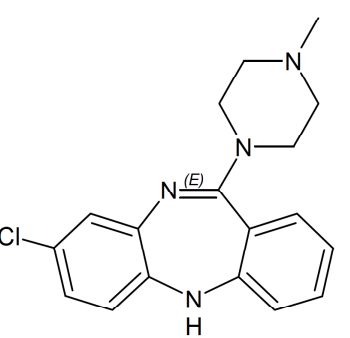

clozapine

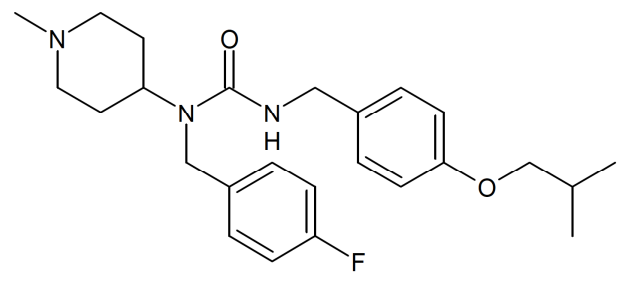

pimavanserin

Fig. (1). Chemical structure of antipsychotic drugs. 
Previously, in preclinical studies it has been identified as ACP-103. The clinically tested compound contains pimavanserin and tartrate in a 2:1 ratio, the molecular weight is $1005.12 \mathrm{~g} / \mathrm{mol}$.

Pimavanserin is a highly selective inverse agonist of the $5-\mathrm{HT}_{2 \mathrm{a}}$ receptor, it displaced the binding of $[3 \mathrm{H}]$ ketanserin to $5-\mathrm{HT}_{2 \mathrm{~A}}$ receptors in both membranes and whole cells with mean $\mathrm{p} K_{\mathrm{i}}$ values of 9.30 and 9.70 in membranes and whole cells, respectively. The drug's potency and efficacy as $5-\mathrm{HT}_{2 \mathrm{a}}$ receptor inverse agonist was determined using the cell-based functional assay R-SAT (Receptor Selection and Amplification Technology ${ }^{\mathrm{TM}}$ ) with a mean $\mathrm{pIC}_{50}$ of 8.73 and $93 \%$ inhibition.

Pimavanserin is also a ligand for $5-\mathrm{HT}_{2 \mathrm{c}}$ receptors, but with a much lower affinity (mean $\mathrm{p} K_{\mathrm{i}} 8.80$ in membranes and 8.00 in whole cells, as determined by radioligand binding), and it's potency as an inverse agonist for $5-\mathrm{HT}_{2 \mathrm{c}}$ receptors was determined with a mean $\mathrm{pIC}_{50}$ of 7.04 , and $110 \%$ inhibition in $\mathrm{R}_{-\mathrm{SAT}}^{\mathrm{TM}}$. Experimental data also indicated, that it has no effect on the $5-\mathrm{HT}_{2 \mathrm{~b}}$ receptors, the dopamine D2 receptor or any other G-protein coupled receptors [58].

In addition, pimavanserin was able to attenuate characteristic behavioral changes in rats, e.g. head-twitches and prepulse inhibition induced by $( \pm)$-2,5-dimethoxy-4iodoamphetamine hydrochloride. It also reduced hyperactivity induced by an N-methyl-D-aspartate receptor antagonist [58].

The pharmacokinetic parameters of pimavanserin have been established in healthy young male volunteers. The compound was evaluated after both single and multiple oral doses in two single-center, randomized, double-blind, placebo-controlled, escalating dose studies [59]. In the first study, pimavanserin was administered in single doses ranging from 20 to $300 \mathrm{mg}$ /day with equal doses of placebo, whereas in the second study, subjects took 50, 100 or 150 mg fixed daily dose of pimavanserin for 14 days, with control subjects receiving a single daily dose. The serum halflife of pimavanserin was around $55-57 \mathrm{~h}$, with a $\mathrm{T}_{\max }$ being at $6 \mathrm{~h}$. These values were independent from the administered doses. The analysis revealed that pimavanserin is highly protein-bound (more than 91\%) [59]. The inter-subject variability of the parameters was low. Data referred to the oral solution of the compound, which was administered either in the form of a solution directly, through a nasogastric tube or in the larger doses, in plastic capsules. However, later an immediate-release, coated tablet was formulated [60]. The oral solution and the coated tablet displayed similar pharmacokinetic parameters, maximum plasma concentrations and similar $t_{\max }$ values, consequently, the two formulations were considered bioequivalent [61]. In the same study the effect of food intake was also assessed, the results indicated, that it did not alter the absorption or other pharmacokinetic parameters of pimavanserin [61].

No serious adverse events could be detected in the first study. The most common, mild, adverse event was postural dizziness observed after taking higher doses of pimavanserin. There were two subjects, receiving 200 and $300 \mathrm{mg}$ dose respectively who experienced vasovagal episodes with bradycardia and a 2 to 8 and 2.9 second pause, which then returned to normal values. These alterations were not considered clinically significant [59]. In the second study there were again no severe adverse events. Mild tremors, nausea and vomiting were reported. One subject, who received 150 $\mathrm{mg}$ dose of pimavanserin, experienced a vasovagal episode with an approximately 15 second pause, which later returned to normal and was not considered clinically relevant. One subject, who received a $100 \mathrm{mg}$ dose, met outlier criteria for PR and QRS intervals intermittently, which were absent at baseline. Additionally, there were seven subjects who met outlier criteria for QT intervals at least one time. Readings showed QT intervals greater than $430 \mathrm{~ms}$, which were absent at baseline.

After promising preclinical results, the first clinical study aimed to assess the safety and tolerability of the drug in patients with PDP. This initial, double-blind, placebocontrolled study involved only 12 patients, who received placebo, $25 \mathrm{mg}$, and $100 \mathrm{mg}$ of pimavanserin, respectively, for 14 days. Results indicated safety and tolerability [62]. There followed a phase II double-blind study, which recruited 60 PD patients with hallucinations and delusions. The aim of the study was again the evaluation of tolerability and safety, but with an initial outlook on whether the drug is able to attenuate psychotic symptoms. Antiparkinsonian therapy was stable during the study. Patients were randomly assigned to placebo or $20 \mathrm{mg}$ of pimavanserin, with the possibility of dose increase to 40 or $60 \mathrm{mg}$ during the study, according to patients' needs. At the closure of the study, pimavanserin dose escalated to $44.8 \mathrm{mg}$, whereas the equivalent, placebo dose was $55.9 \mathrm{mg}$. This study confirmed that the side-effects did not differ significantly from placebo and pimavanserin did not worsen motor symptoms. Moreover, a good effect could be detected on the scale for assessment of positive symptoms (SAPS) hallucinations and delusions domains and significant attenuation of psychosis on the global item ratings of hallucinations and delusions [62]. On the other hand, no significant difference could be seen in the primary outcome measure of the SAPS total domain score for delusions and hallucinations. No severe adverse event was recorded related to the study. Syncope with bradycardia did not occur. The milder adverse events detected were edema, somnolence and elevation in blood urea nitrogen. One patient dropped out of the study because of worsening hallucinations.

After the promising results of the phase II trial, a larger international PDP study was conducted (ACP-103-012), which involved 298 PDP patients who received either placebo, $10 \mathrm{mg}$ or $40 \mathrm{mg}$ pimavanserin once a day for 6 weeks. Although there were signs of effectiveness, this did not reach statistical significance on the SAPS hallucinations and delusions scale. The result was accredited to an unexpectedly large placebo response [62]. Another international trial (ACP-103-014) was also launched, enrolling only 123 PDP patients, but was stopped early after the results of the previous (ACP-103-012) were becoming obvious. From the three arm (placebo, 10 and $20 \mathrm{mg}$ pimavanserin) study, the $20 \mathrm{mg}$ group seemed to show effectiveness without statistical significance on SAPS hallucination+delusion scale.

After some methodological changes, a Phase III trial (ACP-103-020) was initiated, which later showed efficacy of pimavanserin $34 \mathrm{mg}$ /day (administered as pimavanserin 
tartarate 40/mg) in all evaluated endpoints. This study involved PD patients with moderate to severe psychosis symptoms assessed by trained, independent raters on video. Item number was decreased from 20 items to 9 on the SAPS scale to better fit PDP patients, leaving out those, which were more suitable for schizophrenia. The new scale was called PD-adapted Scale for Assessment of Positive Symptoms (SAPS-PD) [63]. A two-week psychosocial therapy was given before the beginning of the study. Inclusion criteria was defined as a minimal combined score of 6 on the Neuropsychiatric Inventory or a minimal score of 4 on the individual sections on hallucinations or delusions, and a minimal score of 3 on SAPS-PD. Pimavanserin effectively reduced psychotic symptoms assessed SAPS-PD. A 37\% reduction was found compared to a $14 \%$ reduction achieved by the placebo. Improvement was also seen according to the physician's clinical global impression (clinical global impression severity and improvement scores). Pimavanserin improved sleep quality and daytime wakefullness as well. [64-67]. It is also important to note, that subject age, gender or MMSE score did not influence the results, pimavanserin seemed effective regardless of these variables. Motor symptoms did not worsen. There were 10 withdrawals in the pimavanserin group as opposed to 2 in the placebo. Psychosis symptoms accounted for six withdrawals, four due to psychotic disorder or hallucination within 10 days of start of the study drug. There were 2 deaths due to sepsis in the pimavanserin group and one sudden cardiac death occurred in the control group, however the deaths were not considered study related. A QT interval increase could be detected in the pimavanserin group without additional clinical consequences [64].

The patients participating in the Phase II (ACP-103-006) and Phase III (ACP-103-012, -014, -020) studies were enrolled in further open-label extension studies. Patients who have been receiving the drug were allowed to continue, while those on placebo had the possibility to switch to pimavanserin. Previous phase II patients were followed by the clinical global impression severity scale, whereas the phase III patients were followed by the SAPS and clinical global impression scales. The phase III extension study is still ongoing, interim analysis results confirmed long-term safety and efficacy of pimavanserin [66-69]. SAPS-PD scores showed improvement in case of patients previously on placebo. In case of patients receiving pimavanserin earlier, stabilization of the beneficial effect could be observed, without any serious adverse events. Discontinuation for lack of effectiveness was less than $20 \%[66,68]$.

Another open-label safety extension study examined pimavanserin combined with add-on antipsychotics. Results showed, that in the case of combination of pimvanserin with other antipsychotics, the rate of mortality, adverse events and worsening of parkinsonian symptoms was significantly higher compared to the patients receiving pimavanserin alone [66]. The age, gender, disease parameters and cognitive status was harmonized between the two groups.

To investigate possible application of pimavanserin in other diseases with pscyhosis, phase II studies were initiated in schizophrenia and Alzheimer's disease. The study in patients with Alzheimer's disease is still ongoing, however the phase II study of pimavanserin (ACP-103-008) added on to sub-optimal dosage of other antipsychotic drugs had been completed [70]. $20 \mathrm{mg}$ of pimavanserin given daily in addition to risperidone in a sub-optimal dosage (1 $\mathrm{mg}$ twice daily) resulted in faster effect, equivalent efficacy and better safety than monotherapy with risperidone only [70]. In contrast, the addition of the same dose of pimavanserin to a suboptimal dose of haloperidol ( $2 \mathrm{mg}$ /day) was not more effective than the same dose haloperidol plus placebo [70].

\subsection{Adverse Events}

The assessment of adverse events is mainly based on the experience gained through the phase III, placebo-controlled trial and the open-label safety extension trials, which evaluated once-daily pimavanserin dose of $34 \mathrm{mg}$ compared to placebo (data available from http://www.acadiapharm.com/wp-content/uploads/2016/04/Nuplazidpimavanserin-Package-Insert.pdf).

The most common adverse events, where incidence was $\geq 5 \%$ and at least twice the rate of placebo, were peripheral edema (7\% pimavanserin $34 \mathrm{mg}$ vs $2 \%$ placebo) and confusional state (6\% pimavanserin vs $3 \%$ placebo). Other adverse reactions which led to discontinuation of treatment were hallucination ( $2 \%$ pimavanserin vs $<1 \%$ placebo), urinary tract infection ( $1 \%$ pimavanserin vs $<1 \%$ placebo) fatigue $(1 \%$ pimavanserin vs $0 \%$ placebo), constipation ( $4 \%$ pimavanserin vs 3\% placebo) and gait disturbance (2\% pimavanserin vs $<1 \%$ placebo). (data available from http://www.acadiapharm.com/wp-content/uploads/2016/04/Nuplazidpimavanserin-Package-Insert.pdf).

There were no detected differences between population subgroups in safety on the basis of age or sex. Ethnic differences could not be discerned because the patient population was predominantly Caucasian.

Pimavanserin has the potential to prolong the QT interval, thus it is contraindicated in patients with known QT prolongation and it should not be administered with drugs that are known to prolong the QT interval (data available from http://www.acadia-pharm.com/wp-content/uploads/2016/04/ Nuplazid-pimavanserin-Package-Insert.pdf).

A dosage reduction to $17 \mathrm{mg}$ is advised when pimavanserin is administered with strong CYP3A4 inhibitors, whereas if it is used with a CYP3A4 inducer, an increase in dosage might be recommended. Adjustment of pimavanserin dosage is not needed when administered together with levodopa, according to drug interaction studies. (Data available from http://www.acadia-pharm.com/wp-content/uploads/ 2016/04/Nuplazid-pimavanserin-Package-Insert.pdf). However, pimavanserin is not recommended in patients with severe renal or hepatic impairment. Pimavanserin has a black box warning of increased mortality in elderly patients with dementia-related psychosis and the drug is not approved for dementia-related psychosis symptoms unrelated to the psychotic symptoms of PDP. Treatment with atypical antipsychotics increased the risk of death significantly in 17 analysed trials (data available from http://www.acadiapharm.com/wp-content/uploads/2016/04/Nuplazidpimavanserin-Package-Insert.pdf). 


\section{DISCUSSION}

Several neurotransmitter systems have been implicated in the pathogenesis of Parkinson's disease. Although dopaminergic deficit is considered the hallmark of the disease, substantial contribution of serotonergic, cholinergic and glutamatergic dysfunction has also been recognized. Serotonergic neurons of the raphe nucleus are affected early in the course of the disease with gradual deterioration of serotonergic projections to the striatum, frontal and temporal lobes [71]. Consistent with the Braak staging, Lewy body deposition of the caudal brainstem raphe nuclei is observed in Braak stage two, previous to that seen in midbrain dopaminergic neurons [72]. PET studies on early, established and advanced PD patients have shown that there is a nonlinear reduction of 5-HT receptor activity throughout the course of the disease which is not related to disease duration, motor function or dopamine replacement therapy. Serotonergic neurons are involved differently from dopaminergic neurons, with neurons affected more in the caudate than in the putamen [72]. The reduction of serotonergic neurons can likely cause a compensatory upregulation of post-synaptic $5 \mathrm{HT}_{2 \mathrm{~A}}$ receptors which results in an imbalance in the function of these receptors. The dysregulated dopamine release from remainding serotonergic reminals in the form of a ,false neurotransmitter", after dopamine replacement therapy, can also contribute to the hypersensitivity of serotonin receptors [73]. At the end, overstimulation of $5 \mathrm{HT}_{2 \mathrm{~A}}$ receptors leads to hallucinations in PD [53, 55].

In light of these pathomechanisms the rationale for the development of $5 \mathrm{HT}_{2 \mathrm{~A}}$ receptor influencing drugs is well substantiated.

Pimavanserin, through its selective inverse agonistic effect on $5-\mathrm{HT}_{2 \mathrm{a}}$ receptors, is the first drug approved by the FDA for the treatment of hallucinations and delusions associated with Parkinson's disease [67]. The completed phase II and phase III studies as well as the interim analysis of the ongoing open label extension studies showed good tolerability, safety and efficacy in the treatment of PDP. A metaanalysis of all the studies by Yasue et al. reported that pimavanserin was associated with less orthostatic hypotension than placebo and there were no significant differences in rates of all-cause discontinuation, adverse events, and death, UPDRS-II+III scores, and incidences of individual adverse events (other than orthostatic hypotension) between pimavanserin and placebo groups. No negative modulator was found for the 5- $\mathrm{HT}_{2 \mathrm{~A}}$ receptor [74]. Overall, data are very promising. Pimavanserin has shown no negative impact on motor symptoms of patients and it also lacks the possible serious side-effects of the previously used medications. The side effect profile is mild with only two: peripheral edema and confusion having the incidence rate of more than $5 \%$ and twice as the rate of placebo. The rest of the adverse reactions (hallucination, urinary tract infection, constipation, gait disturbance, fatigue), which led to the discontinuation of treatment during the studies, occur only with the incidence rate of less than 5\%. Pimavanserin can prolong the QT interval, thus baseline ECG is needed and possible drug-interactions have to be monitored. However this is also the case with clozapine and quetiapine as well. It is also important to note, that during the phase II testing of the drug, at higher doses (four to seven times the dose recommended), vasaovagal episodes were reported. Thus, a dose increase should be ruled out, especially in the older population, even if the patient is not responding as well and the physician would likely think of dose escalation.

Until now, only interim analyses have been available for the open-label extension studies. These data will be important in the longrun for the identification of possible late sideeffects. Strict post-marketing monitoring is needed to further ensure safety with long-time use. As in the case of agranulocytosis caused by clozapine, possible rare side effects can be recognised only with the drug tried on a larger population.

A very important characteristic of the drug, that must also be emphasized, is that no differences could be detected between population subgroups in safety on the basis of age or sex. A good safety profile was determined for older patient populations with PDP without dementia. However, if other antipsychotics were added on to pimavanserin, the risk of mortality, adverse events increased significantly, with worsening of other Parkinsonian symptoms. This led to the black box warning for treatment with pimavanserin in dementia related psychosis. The above mentioned observations are also crucial when treating non- or slowly responding patients. Frequently, for them, extra measures are needed and the long half life of pimavanserin contributes to the dilemma. In case of patients who need rapid treatment for fulminant psychotic symptoms, there might not be enough time to reach pimavanserin steady state. Combination therapy with other antipsychotics may be necessary at the initiation of treatment. Protocols for these situations must be determined in the future.

In the phase II studies, PD patients with a spectrum of disease subtypes and severities were randomized, whereas in the phase III study, after refinement of the protocol, only moderately and severely psychotic patients were included. There were no exclusion criteria for certain kinds of PD medications. Patients could be treated with all of the drugs on the therapeutic palette. This means that throughout the studies drug interactions could be evaluated between pimavanserin and other PD therapy. The conclusion was that no interaction could be observed between pimavanserin and levodopa, dopamine agonist or other PD medication, which will help the addition of pimavanserin to other PD therapies in all types of patients.

Pimavanserin's good tolerability and safety profile will most certainly advance the introduction of the "antipsychotic drug" in the therapeutic scheme. While clozapine and quetiapine were introduced usually after serious consideration, only when psychotic symptoms were devastating, this new drug, developed with the specific intention of PDP treatment, could be used at the first appearance of psychotic alterations, making everyday life more acceptable for the patient and decreasing caretaker burden. The number of PD and PDP patients is increasing world-wide, and an antipsychotic drug, which is easy-to-use, might even facilitate clinicians to evaluate patients more precisely for early signs of psychosis in PD. As a recent report has shown minor hallucinations can occur in drug-naive PD patients even in the premotor phase [75]. 
Table 1. Summary of antipsychotic drugs to treat PDP.

\begin{tabular}{|c|c|c|c|}
\hline Drug name & Dose & Possible side-effects & Monitoring needs \\
\hline \hline Clozapine & $6.25-50 \mathrm{mg} / \mathrm{day}$ & $\begin{array}{c}\text { Sedation, orthostatic hypotension, hypersalivation, } \\
\text { agranulocytosis, neutropenia, NMS }\end{array}$ & $\begin{array}{c}\text { Compulsory blood monitoring during treatment for } \\
\text { agranulocytosis, neutrophil and white blood cell count, } \\
\text { baseline ECG for QT prolongation }\end{array}$ \\
\hline Quetiapine & $50-150 \mathrm{mg} / \mathrm{day}$ & $\begin{array}{c}\text { Sedation, orthosthatic hypotension, headache, } \\
\text { dizziness, NMS }\end{array}$ & Baseline ECG for QT prolongation \\
\hline Pimavanserin & $34 \mathrm{mg} / \mathrm{day}$ & $\begin{array}{c}\text { Peripheral edema, confusion, hallucination, urinary tract } \\
\text { infection, fatigue, constipation, gait disturbance, }\end{array}$ & Baseline ECG for QT prolongation \\
\hline
\end{tabular}

There are other potential uses of pimavanserin. Data from the Phase III study showed that the sleep quality of the patients improved and a good effect could be observed in daytime wakefullness as well $[64,65]$. Earlier studies have also suggested that $5-\mathrm{HT}_{2 \mathrm{~A}}$ receptor antagonists and pimavanserin enhance slow-wave sleep [76]. This effect might later have therapeutic consequences as well.

The specific treatment of psychotic symptoms in various types of dementia constitutes a major demand. Medication of elderly, demented patients is extremely difficult. The use of both typical and atypical antipsychotic drugs increases the mortality and morbidity and comorbidities add to the therapeutic risk. Pimavanserin with a better side-effect profile might rapidly outplace other medications. A study with Alzheimer's disease patients has been initiated and is still ongoing. However, the treatment of psychotic symptoms in diffuse Lewy body disease and Huntington's disease would also be warranted.

Studies in the treatment of schizophrenia with pimavanserin have been launched. Pimavanserin enhanced the effect of sub-optimal dose of risperidone with equal efficacy and better safety than risperidone monotherapy. As an augmentation drug to haloperidol, however, the same result could not be achieved [70]. The reason behind the ineffectivity was suspected to be the dosage of haloperidol being significantly below the neuroleptic threshold. Dosage adjustment of haloperidol might lead to better results in combination with pimavanserin.

A frequent non-motor symptom of PD is depression. Serotonergic involvement in the development of depression is supported by the observations that tryptophan depletion can result in depression and that symptoms react well to selective-serotonin reuptake inhibitors [77]. Chronic levodopa treatment might result in PD depression through serotonin depletion because of the competition for storage in serotonergic vesicles during the conversion of levodopa into dopamine [78]. Data also show, that a decrease can be detected in the cerebrospinal fluid levels of 5-hydroxyindoleacetic acid, a main metabolite of serotonin, in PD patients with depression compared to those without [79].

On the whole, studies suggest, that in PD depression, the decrease of extracellular serotonin concentration is enhanced through serotonin clearance by the serotonin transporter. The level of serotonin is further decreased by the deterioration of serotonergic neurons in the raphe nuclei and limbic regions.
Additionally, a disproportionate upregulation of 5-HT receptors parallels these processes. These pathomechanisms could be influenced by agents which hinder these processes, possibly acting on serotonin transporters or on serotonin receptors [72]. The potential part of pimavanserin in PD depression has not been investigated.

The role of serotonin has been emphasized in connection with other PD non-motor symptoms as well, like fatigue, weight loss and obsessive-compulsive disorder. However further reasearch is needed to characterize the precise component of the pathomechanisms which could be addressed by novel medication. The effect of pimavanserin has not been evaluated in these aspects.

Serotonin receptors have also been implicated in PD motor symptoms. Initially it was clozapine, which showed a significant effect in influencing levodopa-induced-dykinesias (LID) and tremor [29, 30]. Later, however, 5-HT receptormediated mechanisms were suspected in the background. An animal study reported that pimavanserin reduced tremor in a rat model and levodopa-induced dyskinesias in a monkey model, however this has not been confirmed in human studies [80]. On the other hand, recent data indicated that striatal serotonergic terminals contribute to LIDs pathophysiology via aberrant processing of exogenous levodopa and release dopamine as a false neuro-transmitter in the denervated striatum of PD patients with LIDs. The use of selective serotonin receptor type $1 \mathrm{~A}$ agonists, rather than $5-\mathrm{HT}_{2 \mathrm{~A}}$ inverse agonists, were suggested as antidyskinetic agents in PD [25].

On the whole, pimavanserin offers a wide spectrum of treatment possibilities and it's approval is a critical step in the treatment of psychosis in Parkinson's disease patients. It represents a precise approach to influencing a specific disease symptom. It's efficacy, safety and tolerability can become a useful tool in the antipsychotic regimen in PDP and possibly in other neuropsychiatric illnesses.

\section{CONCLUSION}

The pharmacological management of PDP has not been resolved in the past few years. The most frequently used medications have been clozapine and quetiapine, whose use in the therapeutic regimen have been associated with various side-effects. Pimavanserin is a selective $5-\mathrm{HT}_{2 \mathrm{a}}$ receptor inverse agonist with a good oral bioavailability. Clinical trials have confirmed its efficacy to improve PDP with excellent tolerability, safety and a benign effect on motor function. 
Pimavanserin has gained FDA approval in April 2016. It is therefore likely that it can become a valuable drug in the future for the treatment of PDP.

\section{LIST OF ABBREVIATIONS}

\begin{tabular}{|c|c|c|}
\hline APD & $=$ & Atypical Antipsychotics \\
\hline FDA & $=$ & Food and Drug Administration \\
\hline LID & $=$ & Levodopa-Induced-Dykinesias \\
\hline NMS & $=$ & Neuroleptic Malignant Syndrome \\
\hline PD & $=$ & Parkinson's Disease \\
\hline PDP & $=$ & Parkinson's Disease Psychosis \\
\hline $\mathrm{R}_{-\mathrm{SAT}}^{\mathrm{TM}}$ & $=$ & $\begin{array}{l}\text { Receptor Selection and Amplification Tech- } \\
\text { nology }\end{array}$ \\
\hline SAPS & $=$ & Scale for Assessment of Positive Symptoms \\
\hline SAPS-PD & $=$ & $\begin{array}{l}\text { PD-Adapted Scale for Assessment of Posi- } \\
\text { tive Symptoms }\end{array}$ \\
\hline $5-\mathrm{HT}_{2 \mathrm{a}}$ & $=$ & Serotonin 2a Receptor \\
\hline
\end{tabular}

\section{CONFLICT OF INTEREST}

The authors confirm that this article content has no conflict of interest.

\section{ACKNOWLEDGEMENTS}

This work was supported by the project TÁMOP4.2.6.3.1., the Hungarian Brain Research Program (NAP, Grant No. KTIA 13 NAP-A-III/9 and KTIA 13 NAP-AII/17.), and the MTA-SZTE Neuroscience Research Group of the Hungarian Academy of Sciences and the University of Szeged.

\section{REFERENCES}

[1] Findley LJ. The economic impact of Parkinson's disease. Parkinsonism Relat Disord. 2007; 13 Suppl: S8-S12.

[2] Fenelon G, Soulas T, Zenasni F, Cleret de Langavant L. The changing face of Parkinson's disease-associated psychosis: a crosssectional study based on the new NINDS-NIMH criteria. Mov Disord. 2010; 25(6): 763-6.

[3] Goetz CG, Stebbins GT, Ouyang B. Visual plus nonvisual hallucinations in Parkinson's disease: development and evolution over 10 years. Mov Disord. 2011; 26(12): 2196-200.

[4] Friedman JH. Parkinson disease psychosis: Update. Behav Neurol. 2013; 27(4): 469-77.

[5] Ravina B, Marder K, Fernandez HH, Friedman JH, McDonald W, Murphy D, et al. Diagnostic criteria for psychosis in Parkinson's disease: report of an NINDS, NIMH work group. Mov Disord. 2007; 22(8): 1061-8.

[6] Wint DP, Okun MS, Fernandez HH. Psychosis in Parkinson's disease. J Geriatr Psychiatry Neurol. 2004; 17(3): 127-36.

[7] Chou KL, Messing S, Oakes D, Feldman PD, Breier A, Friedman JH. Drug-induced psychosis in Parkinson disease: phenomenology and correlations among psychosis rating instruments. Clin Neuropharmacol. 2005; 28(5): 215-9.

[8] Fenelon G, Alves G. Epidemiology of psychosis in Parkinson's disease. J Neurol Sci. 2010; 289(1-2): 12-7.

[9] Merims D, Shabtai H, Korczyn AD, Peretz C, Weizman N, Giladi N. Antiparkinsonian medication is not a risk factor for the development of hallucinations in Parkinson's disease. J Neural Transm (Vienna). 2004; 111(10-11): 1447-53.
[10] Goetz CG, Pappert EJ, Blasucci LM, et al. Intravenous levodopa in hallucinating Parkinson's disease patients: high-dose challenge does not precipitate hallucinations. Neurology 1998; 50(2): 515-7.

[11] Munhoz RP, Teive HA, Eleftherohorinou H, Coin LJ, Lees AJ, Silveira-Moriyama L. Demographic and motor features associated with the occurrence of neuropsychiatric and sleep complications of Parkinson's disease. J Neurol Neurosurg Psychiatry 2013; 84(8): 883-7.

[12] Chang A, Fox SH. Psychosis in Parkinson's Disease: Epidemiology, Pathophysiology, and Management. Drugs 2016; 76(11): 1093-118.

[13] Forsaa EB, Larsen JP, Wentzel-Larsen T, et al. A 12-year population-based study of psychosis in Parkinson disease. Arch Neurol 2010; 67(8): 996-01.

[14] Goldman JG. New thoughts on thought disorders in Parkinson's disease: review of current research strategies and challenges. Parkinsons Dis 2011; 2011: 675630 .

[15] Ishihara L, Brayne C. A systematic review of depression and mental illness preceding Parkinson's disease. Acta Neurol Scand 2006; 113(4): 211-20.

[16] Arabia G, Grossardt BR, Geda YE, et al. Increased risk of depressive and anxiety disorders in relatives of patients with Parkinson disease. Arch Gen Psychiatry 2007; 64(12): 1385-92.

[17] Schuurman AG, van den Akker M, Ensinck KT, et al. Increased risk of Parkinson's disease after depression: a retrospective cohort study. Neurology 2002; 58(10): 1501-4.

[18] Srivastava A, Tang MX, Mejia-Santana H, Rosado L, Louis ED, Caccappolo E, et al. The relation between depression and parkin genotype: the CORE-PD study. Parkinsonism Relat Disord 2011; 17(10): 740-4

[19] Lin HL, Lin HC, Chen YH. Psychiatric diseases predated the occurrence of Parkinson disease: a retrospective cohort study. Ann Epidemiol 2014; 24(3): 206-13.

[20] Shiba M, Bower JH, Maraganore DM, et al. Anxiety disorders and depressive disorders preceding Parkinson's disease: a case-control study. Mov Disord 2000; 15(4): 669-77.

[21] Lenka A, Arumugham SS, Christopher R, Pal PK. Genetic substrates of psychosis in patients with Parkinson's disease: A critical review. J Neurol Sci 2016; 364: 33-41.

[22] Oeda T, Umemura A, Mori Y, et al. Impact of glucocerebrosidase mutations on motor and nonmotor complications in Parkinson's disease. Neurobiol Aging 2015; 36(12): 3306-13.

[23] Hindle JV. The practical management of cognitive impairment and psychosis in the older Parkinson's disease patient. J Neural Transm 2013; 120(4): 649-53.

[24] Meltzer HY, Matsubara S, Lee JC. Classification of typical and atypical antipsychotic drugs on the basis of dopamine D-1, D-2 and serotonin 2 pKi values. J Pharmacol Exp Ther 1989; 251(1): 23846.

[25] Group TPS. Low-dose clozapine for the treatment of drug-induced psychosis in Parkinson's disease. The Parkinson Study Group. N Engl J Med 1999; 340(10): 757-63.

[26] Thomas AA, Friedman JH. Current use of clozapine in Parkinson disease and related disorders. Clin Neuropharmacol 2010; 33(1) 14-6.

[27] Pollak P, Tison F, Rascol O, et al. Clozapine in drug induced psychosis in Parkinson's disease: a randomised, placebo controlled study with open follow up. J Neurol Neurosurg Psychiatry 2004; 75(5): 689-95.

[28] Seppi K, Weintraub D, Coelho M, et al. The Movement Disorder Society Evidence-Based Medicine Review Update: Treatments for the non-motor symptoms of Parkinson's disease. Mov Disord 2011; 26 Suppl 3: S42-80.

[29] Friedman JH, Lannon MC. Clozapine-responsive tremor in Parkinson's disease. Mov Disord 1990; 5(3): 225-9.

[30] Bennett JP, Jr., Landow ER, Schuh LA. Suppression of dyskinesias in advanced Parkinson's disease. II. Increasing daily clozapine doses suppress dyskinesias and improve parkinsonism symptoms. Neurology 1993; 43(8): 1551-5.

[31] Arana GW. An overview of side effects caused by typical antipsychotics. J Clin Psychiatry 2000; 61 Suppl 8: 5-11

[32] Goldman JG, Holden S. Treatment of psychosis and dementia in Parkinson's disease. Curr Treat Options Neurol 2014; 16(3): 281.

[33] Fernandez HH, Friedman JH, Lansang MC, Factor SA, Molho ES, Coskun DJ. Diabetes mellitus among parkinsonian patients treated 
chronically with clozapine. Parkinsonism Relat Disord 2004; 10(7): 439-41.

[34] Gardell LR, Vanover KE, Pounds L, et al. ACP-103, a 5hydroxytryptamine $2 \mathrm{~A}$ receptor inverse agonist, improves the antipsychotic efficacy and side-effect profile of haloperidol and risperidone in experimental models. J Pharmacol Exp Ther 2007; 322(2): 862-70.

[35] Kapur S, Seeman P. Antipsychotic agents differ in how fast they come off the dopamine D2 receptors. Implications for atypical antipsychotic action. J Psychiatry Neurosci 2000; 25(2): 161-6.

[36] Fernandez HH, Friedman JH, Jacques C, Rosenfeld M. Quetiapine for the treatment of drug-induced psychosis in Parkinson's disease. Mov Disord 1999; 14(3): 484-7.

[37] Prohorov T, Klein C, Miniovitz A, Dobronevsky E, Rabey JM. The effect of quetiapine in psychotic Parkinsonian patients with and without dementia. An open-labeled study utilizing a structured interview. J Neurol 2006; 253(2): 171-5.

[38] Ondo WG, Tintner R, Voung KD, Lai D, Ringholz G. Doubleblind, placebo-controlled, unforced titration parallel trial of quetiapine for dopaminergic-induced hallucinations in Parkinson's disease. Mov Disord 2005; 20(8): 958-63.

[39] Rabey JM, Prokhorov T, Miniovitz A, Dobronevsky E, Klein C. Effect of quetiapine in psychotic Parkinson's disease patients: a double-blind labeled study of 3 months' duration. Mov Disord 2007; 22(3): 313-8.

[40] Shotbolt P, Samuel M, Fox C, David AS. A randomized controlled trial of quetiapine for psychosis in Parkinson's disease. Neuropsychiatr Dis Treat 2009; 5: 327-32.

[41] Desmarais P, Massoud F, Filion J, Nguyen QD, Bajsarowicz P. Quetiapine for Psychosis in Parkinson Disease and Neurodegenerative Parkinsonian Disorders: A Systematic Review. J Geriatr Psychiatry Neurol 2016; 29(4): 227-36.

[42] Zhou MZ, Gan J, Wei YR, Ren XY, Chen W, Liu ZG. The association between non-motor symptoms in Parkinson's disease and age at onset. Clin Neurol Neurosurg 2013; 115(10): 2103-7.

[43] Maust DT, Kim HM, Seyfried LS, et al. Antipsychotics, other psychotropics, and the risk of death in patients with dementia: number needed to harm. JAMA psychiatry 2015; 72(5): 438-45.

[44] Weintraub D, Chiang C, Kim HM, et al. Association of Antipsychotic Use With Mortality Risk in Patients With Parkinson Disease. JAMA neurology 2016; 73(5): 535-41.

[45] Schattner A, Kitroser E, Cohen JD. Fatal Neuroleptic Malignant Syndrome Associated With Quetiapine. Am J Ther 2015 Jun 30.

[46] Mesquita J, Siva L. Fatal neuroleptic malignant syndrome induced by clozapine in Parkinson's psychosis. J Neuropsychiatry Clin Neurosci 2014; 26(1): E34.

[47] Stockmeier CA, DiCarlo JJ, Zhang Y, Thompson P, Meltzer HY. Characterization of typical and atypical antipsychotic drugs based on in vivo occupancy of serotonin 2 and dopamine2 receptors. J Pharmacol Exp Ther 1993; 266(3): 1374-84.

[48] Meltzer HY. Update on typical and atypical antipsychotic drugs. Annu Rev Med 2013; 64: 393-06.

[49] Nichols DE. Hallucinogens. Pharmacol Ther 2004; 101(2): 131-81.

[50] Gonzalez-Maeso J, Weisstaub NV, et al. Hallucinogens recruit specific cortical 5-HT(2A) receptor-mediated signaling pathways to affect behavior. Neuron 2007; 53(3): 439-52.

[51] Wiesel FA, Farde L, Nordstrom AL, Sedvall G. Central D1- and D2-receptor occupancy during antipsychotic drug treatment. Prog Neuropsychopharmacol Biol Psychiatry 1990; 14(5): 759-67.

[52] Kessler RM, Ansari MS, Riccardi P, et al. Occupancy of striatal and extrastriatal dopamine D2 receptors by clozapine and quetiapine. Neuropsychopharmacology 2006; 31(9): 1991-01.

[53] Ballanger B, Strafella AP, van Eimeren T, et al. Serotonin 2A receptors and visual hallucinations in Parkinson disease. Arch Neurol 2010; 67(4): 416-21.

[54] Chen CP, Alder JT, Bray L, Kingsbury AE, Francis PT, Foster OJ. Post-synaptic 5-HT1A and 5-HT2A receptors are increased in Parkinson's disease neocortex. Ann N Y Acad Sci 1998; 861: 2889.

[55] Huot P, Johnston TH, Darr T, et al. Increased 5-HT2A receptors in the temporal cortex of parkinsonian patients with visual hallucinations. Mov Disord 2010; 25(10): 1399-08.

[56] Zoldan J, Friedberg G, Livneh M, Melamed E. Psychosis in advanced Parkinson's disease: treatment with ondansetron, a 5-HT3 receptor antagonist. Neurology 1995; 45(7): 1305-8.
Sirota P, Mosheva T, Shabtay H, Giladi N, Korczyn AD. Use of the selective serotonin 3 receptor antagonist ondansetron in the treatment of neuroleptic-induced tardive dyskinesia. Am J Psychiatry 2000; 157(2): 287-9.

[58] Vanover KE, Weiner DM, Makhay M, et al. Pharmacological and behavioral profile of N-(4-fluorophenylmethyl)-N-(1methylpiperidin-4-yl)-N'-(4-(2-methylpropyloxy)phen ylmethyl) carbamide (2R,3R)-dihydroxybutanedioate (2: 1) (ACP-103), a novel 5-hydroxytryptamine $(2 \mathrm{~A})$ receptor inverse agonist. J Pharmacol Exp Ther 2006; 317(2): 910-8.

[59] Vanover KE, Robbins-Weilert D, Wilbraham DG, et al. Pharmacokinetics, tolerability, and safety of ACP-103 following single or multiple oral dose administration in healthy volunteers. J Clin Pharmacol 2007; 47(6): 704-14.

[60] Vanover KE, Robbins-Weilert D, Wilbraham DG, et al. The effects of food on the pharmacokinetics of a formulated ACP-103 tablet in healthy volunteers. J Clin Pharmacol 2007; 47(7): 915-9.

[61] Vanover KE, Robbins-Weilert D, Wilbraham DG, et al. The effects of food on the pharmacokinetics of a formulated ACP-103 tablet in healthy volunteers. J Clin Pharmacol 2007; 47(7): 915-9.

[62] Hacksell U, Burstein ES, McFarland K, Mills RG, Williams H. On the discovery and development of pimavanserin: a novel drug candidate for Parkinson's psychosis. Neurochem Res 2014; 39(10): 2008-17.

[63] Voss T, Bahr D, Cummings J, Mills R, Ravina B, Williams H. Performance of a shortened Scale for Assessment of Positive Symptoms for Parkinson's disease psychosis. Parkinsonism Relat Disord 2013; 19(3): 295-9.

[64] Cummings J, Isaacson S, Mills R, et al. Pimavanserin for patients with Parkinson's disease psychosis: a randomised, placebocontrolled phase 3 trial. Lancet 2014; 383(9916): 533-40.

[65] Mills R, Bahr D, Chi-Burris K, Williams H. Improved nighttime sleep and increased daytime wakefulness in patients with Parkinson's disease psychosis treated with pimavanserin, a selective 5HT2A antagonist. Mov Disord 2013; 28: S225-S.

[66] Hermanowicz S, Hermanowicz N. The safety, tolerability and efficacy of pimavanserin tartrate in the treatment of psychosis in Parkinson's disease. Expert Rev Neurother 2016.

[67] Markham A. Pimavanserin: First Global Approval. Drugs. 2016; 76(10): 1053-7.

[68] Mills R, Williams H, Bahr D, Chi-Burris K, Ballard C. Long term pimavanserin treatment for Parkinson's disease psychosis (PDP) An interim analysis of safety and tolerability. Mov Disord 2013; 28: S176-S7.

[69] Mills R, Isaacson S, Azulay J, et al. Long-term effectiveness of NUPLAZID $^{\mathrm{TM}}$ (pimavanserin) in PD psychosis: Data from 2 openlabel studies. Parkinsonism Relat Disord 2016; 22(Suppl.2.): e92e3.

[70] Meltzer HY, Elkis H, Vanover K, Weiner DM, et al. Pimavanserin, a selective serotonin (5-HT)2A-inverse agonist, enhances the efficacy and safety of risperidone, $2 \mathrm{mg}$ /day, but does not enhance efficacy of haloperidol, $2 \mathrm{mg} /$ day: comparison with reference dose risperidone, 6mg/day. Schizophr Res 2012; 141(2-3): 144-52.

[71] Halliday GM, Blumbergs PC, Cotton RG, Blessing WW, Geffen LB. Loss of brainstem serotonin- and substance P-containing neurons in Parkinson's disease. Brain Res 1990; 510(1): 104-7.

[72] Politis M, Niccolini F. Serotonin in Parkinson's disease. Behav Brain Res 2015; 277: 136-45.

[73] Carta M, Carlsson T, Kirik D, Bjorklund A. Dopamine released from 5-HT terminals is the cause of L-DOPA-induced dyskinesia in parkinsonian rats. Brain 2007; 130(Pt 7): 1819-33.

[74] Yasue I, Matsunaga S, Kishi T, Fujita K, Iwata N. Serotonin 2A Receptor Inverse Agonist as a Treatment for Parkinson's Disease Psychosis: A Systematic Review and Meta-analysis of Serotonin 2A Receptor Negative Modulators. J Alzheimer's Dis 2015; 50(3): 733-40.

[75] Pagonabarraga J, Martinez-Horta S, Fernandez de Bobadilla R, et al. Minor hallucinations occur in drug-naive Parkinson's disease patients, even from the premotor phase. Mov Disord 2016; 31(1): 45-52.

[76] Ancoli-Israel S, Vanover KE, Weiner DM, Davis RE, van Kammen DP. Pimavanserin tartrate, a 5-HT(2A) receptor inverse agonist, increases slow wave sleep as measured by polysomnography in healthy adult volunteers. Sleep Med 2011; 12(2): 134-41. 
[77] Bell CJ, Hood SD, Nutt DJ. Acute tryptophan depletion. Part II: clinical effects and implications. Aust N Z J Psychiatry 2005; 39(7): 565-74.

[78] Eskow Jaunarajs KL, Dupre KB, Ostock CY, Button T, Deak T, Bishop C. Behavioral and neurochemical effects of chronic LDOPA treatment on nonmotor sequelae in the hemiparkinsonian rat. Behav Pharmacol 2010; 21(7): 627-37.
[79] Mayeux R, Stern Y, Williams JB, Cote L, Frantz A, Dyrenfurth I. Clinical and biochemical features of depression in Parkinson's disease. Am J Psychiatry 1986; 143(6): 756-9.

[80] Vanover KE, Betz AJ, Weber SM, et al. A 5-HT2A receptor inverse agonist, ACP-103, reduces tremor in a rat model and levodopa-induced dyskinesias in a monkey model. Pharmacol Biochem Behav 2008; 90(4): 540-4. 